\title{
Conflict of interest: a long way ahead
}

\author{
P. K. Garg • B. K. Jain
}

Received: 12 December 2011/ Accepted: 23 February 2012/Published online: 22 March 2012

(C) Springer-Verlag 2012

\section{Dear Sir,}

The issue of conflict of interest has been an important concern in the field of medical research in recent years. With an increasing degree of partnership between industry and academic medicine, and a number of incentives (commercial, academic, political, and financial) being available for researchers, it cannot be denied that the possibility of conflict of interest exists.

The International Committee of Medical Journal Editors (ICMJE), in their "Uniform Requirements for Manuscripts Submitted to Biomedical Journals: Writing and Editing for Biomedical Publication" states that "conflict of interest exists when an author (or the author's institution), reviewer, or editor has financial or personal relationships that inappropriately influence (bias) his or her actions (such relationships are also known as dual commitments, competing interests, or competing loyalties)." Moreover, the ICMJE further elaborates that "the potential for conflict of interest can exist regardless of whether an individual believes that the relationship affects his or her scientific judgment" [1].

In 2011, a total of 36 original articles were published in the four issues of the 15th volume of Techniques in Coloproctology. A conflict of interest statement was published in only $12(33.3 \%)$ original articles (3/8 in March issue, $1 / 8$ in June issue, $1 / 11$ in September issue, and 7/9 in December issue). There may be two reasons for this. Either the authors did not declare the conflict of interest or the editorial board chose not to publish the declaration.

P. K. Garg $(\bowtie) \cdot$ B. K. Jain

Department of Surgery, University College of Medical Sciences and Guru Teg Bahadur Hospital, University of Delhi,

Delhi 110 095, India

e-mail: dr.pankajgarg@gmail.com
We believe that there is a large gap in the awareness among clinical investigators regarding conflict of interest. Accepting the potential for conflict of interest does not label a study as a biased one, or reflect on an author's integrity as a researcher. It merely means that the readers are given the opportunity to use their own judgment regarding the results/conclusions in light of the full disclosure of the facts.

We agree that the ICMJE [1] gives the room for editorial board to decide whether to publish information disclosed by authors about potential conflicts. However, The IJCME [1] further elaborates "If doubt exists, it is best to err on the side of publication." We believe that publishing conflict of interest statement in all articles will be the right step to increase the public trust and credibility of the journal. Moreover, conflict of interest disclosure should not be confined to the original articles. Disclosure of conflict of interest is also important in other categories of articles, such as editorials, letters, and review articles, because it can be more difficult to detect bias in these publication types than in original articles [2].

Conflict of interest The authors declare that no conflict of interest exists.

\section{References}

1. http://www.icmje.org/ethical_4conflicts.html. Accessed 14 Nov 2011

2. Peh WC, Ng KH (2010) Conflict-of-interest, copyright and other declarations. Singapore Med J 51:844-846 